Dossiê: Diálogos do Sul

\title{
Protestos sociais em Moçambique Uma agenda de pesquisa
}

\author{
Social protests in Mozambique
}

A research agenda

Remo Mutzenberg*

Resumo: A África, na última década, passou a ser lócus de investimentos de empresas internacionais, particularmente no campo da exploração de recursos naturais. A empresa brasileira Vale do Rio Doce é uma destas empresas que vem investindo na exploração do carvão em Moçambique. Por um lado, a presença da Vale em Tete-Mz gerou expectativas de desenvolvimento e é considerada como investimento importante para o desenvolvimento econômico do país. Por outro lado, essa presença e seus desdobramentos no campo social, ambiental e frustrações de expectativas da população têm gerado protestos de diferentes ordens. O texto busca situar a presença da Vale do Rio Doce, e de outras empresas brasileiras, em África, no quadro da diplomacia política e econômica brasileira, assumida na última década, e da política de incentivos adotados pelos países em África para atrair investimentos, particularmente em Moçambique. Segue análise da Vale em Moçambique, ao lado de outros projetos de mineração. Destaca-se uma análise das manifestações, ocorridas a partir de 2012, pelos reassentados da Vale, situando esses confrontos como parte visível das tensões geradas pela presença, não só da Vale, pelos megaprojetos de mineração. Coloca-se a questão de como esses confrontos se articulam com um movimento latente, isto é, com os questionamentos em relação à política interna moçambicana relativa aos megaprojetos que estariam produzindo riqueza sem fixá-la no país. Nessa direção, a consolidação das relações entre Brasil e Moçambique (e África), no sentido de se estabelecerem relações verticais ou horizontais, não depende apenas de acordos de cooperação, mas das dinâmicas políticas internas e externas, em que a Vale é apenas um dos atores. O texto, assim, se propõe pontuar questões de pesquisa que dizem respeito a processos sociais e políticos locais conectados transnacionalmente,

* Doutor em Sociologia pela Universidade Federal de Pernambuco, Recife, pós-doutorando no Centro de Estudos Africanos - Iscte/IUL, em Lisboa, Portugal, e professor do Departamento de Sociologia e do PPG em Sociologia da UFPE, em Recife, PE, Brasil. O argumento do presente artigo foi apresentado no Painel Africa's resource blessing: pathways to autonomy in a conflicting donor world na 5th European Conference on African Studies, African dynamics in a multipolarworld-ECAS $2013<$ remutz@gmail.com>.

\begin{tabular}{|l|l|l|l|l|l|}
\hline Civitas & Porto Alegre & v. 14 & n. 1 & p. 137-153 & jan.-abr. 2014 \\
\hline
\end{tabular}


que colocam como quadro geral o debate atual sobre desenvolvimento, dependência e cooperação nas relações Sul-Sul.

Palavras-chave: Política externa brasileira. Desenvolvimento econômico. Protestos sociais. Relações Brasil África. Vale do Rio Doce. Moçambique.

\begin{abstract}
Africa in the past decade has become a place for international business investments, particularly in the areas of natural resources exploitation. The Brazilian company, Vale do Rio Doce, is one of these companies which has invested in coal mining in Mozambique. On the one hand, the presence of this company in Tete-Mz has increased the potential for development and is considered as an important investment for the economic development of the country. On the other hand, this presence and its dealings in the social and environmental areas, frustrating the expectations of the local populations, has created different types of protests. This present text situates the presence of the Vale do Rio Doce and other Brazilian companies in Africa, within the situation of Brazilian political and economic diplomacy undertaken in the past decade as well as the incentives adopted by African countries, in particular Mozambique, to attract investment. The text contains an analysis of the Vale company in Mozambique, together with other mining projects. Attention is given to an analysis of the manifestations which occurred starting in 2012, by the Vale workers [by those resettled by the Vale], situating these confrontations as a visible part of the tension generated not only by the Vale company, but by all the mining megaprojects. The question raised is how these confrontations form part of a latent movement concerned with issues related to Mozambican internal policies relative to the megaprojects which are producing wealth without retaining it within the country. Thus cooperation between Brazil an Mozambique (and Africa) in the sense of establishing vertical and horizontal relations does not depend only on cooperative agreements but also on the internal and external political dynamics, in which the Vale company is only one of the actors. Therefore, the text proposes itself to underline research questions related to connected transnational social and political processes, posing, as a general framework the current debate about development, dependence and South-South cooperation relations.
\end{abstract}

Keywords: Brazilian external political. Economic development. Social protests. Brazil and Africa relations. Vale do Rio Doce. Mozambique.

\title{
Introdução
}

A despeito das avaliações impresumíveis em relação aos condicionantes para investimento em qualquer país, ${ }^{1}$ os países da África, em particular na última década, tornaram-se importante polo de investimentos estrangeiros, atraídos particularmente pela alta quantidade de recursos minerais e pelo aumento do seu preço no mercado internacional. Os interesses por tais recursos são um fator explicativo para o crescimento de investimentos diretos em

\footnotetext{
1 Ao menos são considerados como condicionantes fundamentais: "o quadro macroeconômico; a natureza do ambiente de negócios - a qualidade e o preço de fornecedores, mão de obra, serviços de infraestrutura e outros componentes dos custos; assim como as incertezas institucionais ou regulatórias" (Iglesias e Costa, 2012).
} 
países em África voltados para a construção de infraestruturas com o fim de extrair e escoar esses produtos (Iglesias e Costa, 2012). Além disso, há que se considerar a aposta numa maior estabilidade política em determinados países, bem como a adoção de políticas de incentivos de atração de investimentos por países africanos. Essas estratégias econômicas estão inseridas num contexto de realinhamento geopolítico, o que é particularmente evidente no caso da política externa adotada pelo Brasil na última década. Esse processo se constitui num acontecimento que desloca estruturas discursivas em nível das relações internacionais, nacionais e locais. Novos discursos são articulados e suscitam expectativas, demandas, tensões, muitas vezes apenas latentes, e confrontos frente a desdobramentos não pretendidos. Isto é, momentos em que os significados efetivos dessas relações podem não corresponder à retórica, podendo vir a ser campo de conformidades, tensões, conflitos e confrontos. É nesse sentido que propomos pontuar questões sobre impactos, tensões e conflitos provocados pela presença da Vale do Rio Doce em Moçambique no contexto de redefinições da geopolítica mundial. Esta escolha decorre por se tratar de um megaprojeto, que efetivamente está sendo implementado, a partir do qual se expressam diferentes reações. Busca-se, assim, identificar expectativas, tensões latentes e possíveis confrontos políticos. Para tanto, recorremos a fontes bibliográficas, relatórios e notícias, particularmente veiculadas em sítios eletrônicos. O texto busca, num primeiro momento, situar os investimentos da Vale na conjuntura da política externa assumida pelo estado brasileiro, seguindo uma descrição da abrangência da presença da Vale em África, particularmente em Moçambique e, por fim, questões relativas a tensões, confrontos, demandas, atores e articulações locais e transnacionais.

\section{Novo momento da relação Brasil África}

As relações do Brasil com a África, desde o século 16 aos dias atuais, enfrentaram descontinuidades, seguindo as marés das conjunturas políticas e econômicas nacionais e redefinições da geopolítica internacional. Se no período da história colonial brasileira, como afirma Alberto Costa e Silva (2003), o Atlântico se conformava mais para um rio caudaloso, a unir duas margens que se complementavam num só sistema de produção escravista, situado à margem litorânea americana, e de reprodução de escravos, centrada do lado africano, no período pós-independência do Brasil, os fluxos se intensificaram na direção Norte e uma oscilação entre a interrupção e a recuperação das relações entre o Brasil e África. Diferentes periodizações são propostas para caracterizar tal flutuação. No documento elaborado pelo Banco Mundial e Ipea (2011), por exemplo, são identificados cinco períodos: 
1. História colonial do Brasil - século 16 até o início do século 19 caracterizado pelo tráfico de escravos e pelas interações econômicas e sociais;

2. Independência do Brasil até os anos 1950 - marginalização gradual das relações entre o Brasil e a África e concentração nas relações com a América Latina, a Europa e a América do Norte;

3. No processo de independência e construção dos estados africanos, o Brasil teve que adaptar sua política externa a um ambiente internacional com a presença de governos africanos recém-independentes, porém o faz de forma hesitante, limitado pelas relações tradicionais com Portugal. Do início dos anos 1960 a meados dos anos 1970 ocorre uma reaproximação política e econômica, em que o Atlântico Sul torna-se, para o Brasil, foco importante, tanto do ponto de vista comercial quanto da política externa;

4. Esse processo é interrompido, novamente, com a crise econômica e política brasileira na dedada de 1980, levando a um "esquecimento" da África;

5. A reestruturação econômica, levada a efeito na década de 1990, tanto no Brasil quanto em países africanos, marca o processo recente em que a África retoma um lugar de destaque no discurso da política externa do governo brasileiro.

Observamos que esse processo sofreu interrupções com a crise econômica e política brasileira na dedada de 1980 e a reestruturação econômica levada a efeito na década de 1990, tanto no Brasil quanto em países africanos.

É importante situar a atual reaproximação do Brasil em relação à África e, de modo geral, o direcionamento de seu foco para o Atlântico Sul, que tem início ainda na década de 1960, no quadro da política externa brasileira e suas reorientações. Segundo análise de Vizentini (1999), sob o ponto de vista da diplomacia política e econômica brasileira, identificam-se três momentos: O primeiro foi marcado pela subordinação unilateral ao capitalismo mediterrâneo e norte-atlântico, nos primeiros quatro séculos. No século 19 essa subordinação deu-se sob a hegemonia inglesa, no contexto da construção do espaço nacional brasileiro. No segundo, a partir do final do século 19, essa unilateralidade progressivamente vai se estabilizar sob a hegemonia norteamericana, cuja vinculação estratégica caracterizou o período Vargas e dos governos desenvolvimentistas dos anos 1950. Esta vinculação tinha em vista o desenvolvimento econômico, ou o que se denominou "política externa para o desenvolvimento". É naquele momento que o Brasil busca status de aliado 
privilegiado dos Estados Unidos, conformando uma estratégia de barganha (Vizentini, 1999, p. 136). O terceiro momento se caracteriza pela perspectiva da "multilateralidade". Mesmo que essa orientação tenha emergido nos anos 1950, é a partir de 1960 que ela é assumida de forma explicita nos governos de Jânio Quadros e João Goulart e retomada pelos governos militares na primeira metade dos anos 1970. Visava-se a ampliação dos vínculos internacionais frente à dependência em relação aos Estados Unidos, passando a incluir os eixos Sul-Sul e Sul-Leste. No entanto, como afirmamos anteriormente, nos anos 1980 e 1990 as relações Sul-Sul e Sul-Leste sofreram interrupções. Esta não linearidade relaciona-se com mudanças conjunturais em nível global e ao jogo interno de interesses e no jogo política entre as duas estratégias da diplomacia política e econômica do Brasil (cf. Ribeiro, 2010; Pimentel, 2000).

Para os nossos objetivos cabe observar que a diplomacia brasileira passa a atuar tanto no eixo vertical Norte-Sul, como acentua o eixo horizontal SulSul e o eixo diagonal Sul-Leste ainda no final dos anos 1990 e acentuada, de modo particular, no governo Lula (2003-2010) e mantida no governo Dilma Rousseff. No final dos anos 1990, o chanceler Luiz Felipe Lampreia, então ministro das relações exteriores do governo Fernando Henrique Cardoso, afirmava que a África é um objetivo insubstituível da política externa brasileira. Esse discurso é assumido no governo Lula e passa a incorporá-lo à estratégia da política externa brasileira de modo mais efetivo, quando se afirma que "a África constitui para o Brasil uma obrigação política, moral e histórica" (Amorim, 2003). Nessa última década tem-se acentuado um discurso de cooperação entre o Brasil e países da África, em que se articula um discurso acentuando uma "política estimulada por solidariedade, afinidades históricoculturais, econômicas e políticas e pelo interesse no conhecimento produzido pela troca e pela experimentação mediante parcerias" (Pochmann, 2011). Por ocasião dos 50 anos da União Africana, em 25 de maio de 2013, Dilma Roussef reafirmou a política da relação Sul-Sul, afirmando que

o Brasil quer, não só estabelecer relações comerciais, investir aqui, vender para o país, mas também uma cooperação no padrão Sul-Sul. O que é o padrão Sul-Sul de cooperação? É uma cooperação que não seja opressiva, que seja baseada em vantagens mútuas e valores compartilhados (Lourenço, 2013).

Fica clara a afirmação de uma estratégia de aproximação com países pobres e a construção de uma imagem diferente em comparação às antigas potências imperialistas. Por outro lado, fica a dúvida sobre as condições, numa economia globalizada, e sobre os processos efetivos nestas relações. 
Qual é ou será a correspondência entre intenção e gesto, entre retórica e os procedimentos efetivos?

Paralelo ao discurso de cooperação, em que se salientam parcerias na área da "agricultura, saúde, educação e formação profissional, governo eletrônico, administração pública, meio ambiente, tecnologia da informação, desenvolvimento urbano, saneamento básico, biocombustível, transporte aéreo, turismo, justiça, cultura, direitos humanos e esportes", ${ }^{2}$ evidenciam-se os interesses políticos e econômicos da política externa brasileira em relação aos países africanos como parte de uma estratégia da diplomacia brasileira para conquistar espaço no quadro institucional internacional. ${ }^{3}$

O crescimento do comércio do Brasil com países africanos, que aumentou de US\$ 4 bilhões para US\$ 20 bilhões, entre 2000 e 2010, é um indicador do incremento destas relações econômicas. Na mesma direção, o Banco Nacional de Desenvolvimento Econômico (BNDES) tem investido nas exportações brasileiras. Os investimentos de empresas estatais e privadas brasileiras, em países da África, têm crescido na última década, concentrando-se nas áreas de infraestrutura, energia e mineração. ${ }^{4}$

Mesmo com oscilações, a orientação da política externa brasileira está redefinindo, na última década, a localização das transnacionais brasileiras no contexto mundial em que é sinalizado um crescimento desta presença na África e na Ásia, conforme pode ser observado na Tabela 1:

\section{Tabela 1 - Localização das transnacionais brasileiras}

\begin{tabular}{cccccccc}
\hline Ano & $\begin{array}{c}\text { América } \\
\text { do Sul e } \\
\text { Central }\end{array}$ & $\begin{array}{c}\text { América } \\
\text { do Norte }\end{array}$ & Europa & África & Ásia & Oceania & Total \\
\hline 2008 & $46 \%$ & $17 \%$ & $21 \%$ & $5 \%$ & $11 \%$ & $0 \%$ & $100 \%$ \\
2009 & $53 \%$ & $9 \%$ & $17 \%$ & $5 \%$ & $15 \%$ & $1 \%$ & $100 \%$ \\
2010 & $38,2 \%$ & $12,6 \%$ & $21,1 \%$ & $9,6 \%$ & $16,8 \%$ & $1,7 \%$ & $100 \%$ \\
\hline
\end{tabular}

Fonte: Tabela elaborada a partir dos dados do Ranking das Transnacionais Brasileiras, FDC 2009, 2010 e 2011 .

2 Não é objetivo, aqui, analisar os vários protocolos de intenções e grau de sua implantação das políticas de cooperação, mas evidenciar um discurso que coloca os países africanos na pauta das políticas externas do Brasil.

3 Em relação a esse redirecionamento de interesses políticos e econômicos, distintas abordagens têm sido desenvolvidas. A exemplo, ver Veloso e Luft (2009), Costa (2011), Mundial-Ipea (2011), Vilas-Boas (2011), Garcia (2012), bem como as publicações do Ministério do Desenvolvimento, Indústria e Comércio Exterior.

4 Entre as empresas brasileiras atuantes em África, em termos de volume de vendas e investimento, estão a Andrade Gutierrez, Camargo Correa, Odebrecht, Petrobras, Queiroz Galvão e Vale do Rio Doce (Banco Mundial e Ipea, 2011). 
Considerando a presença dos Brics, no conjunto do continente africano, a presença do Brasil é bastante tímida. ${ }^{5}$

Para além da diplomacia política econômica, há que se considerar o crescente interesse de outros setores da sociedade brasileiros em relação à África, por exemplo, no campo das mídias, das religiões e o que poderíamos denominar como um movimento de baixo, como a conquista da inclusão da história da África nas escolas brasileiras, a articulação de movimentos sociais do Brasil e de países africanos, a exemplo do Movimento dos Trabalhadores Sem-Terra e do movimento feminista, crescente interesse sobre a literatura, além do tradicional interesse no campo da cultura etc. (Soares, 2011; Rosa, 2012, 2012a).

É neste contexto que a Vale do Rio Doce, ou simplesmente a Vale, passou a investir em países do continente africano e inserindo-se num campo concorrido e atrativo para investimentos. Como afirmam Roberto Iglesias e Katarina Costa (2012),

[Nos] últimos anos, a África transformou-se em um polo de atração de investimentos diretos estrangeiros. A abundância de recursos minerais no continente e o aumento dos preços desses produtos no mercado internacional parecem ter sido os motivos principais do crescimento dos investimentos diretos na indústria extrativa e na infraestrutura associada ao escoamento dos recursos naturais.

A Vale está presente, atualmente, na África do Sul, Angola, Gabão, Guiné, Libéria, Malaui, Moçambique, República do Congo e Zâmbia, desenvolvendo diferentes atividades, conforme visualizado no Quadro $1 .^{6}$

No entanto, a extração de minérios pela Vale só iniciou oficialmente com a extração do carvão mineral em Moatize em 2011. Além da Vale, destacam-se a presença de outras empresas brasileiras em Moçambique, como a Odebrecht, a Siemens do Brasil, a Petrobras e a Empresa Brasileira de Pesquisa Agropecuária, entre outras. $\mathrm{Na}$ atividade de extração do carvão mineral, na mesma região onde se encontra a Vale, também está presente a empresa australiana Riversdale Mining Ltd.

\footnotetext{
As análises e o debate sobre os Brics são hoje significativas e é uma questão chave para a possível reconfiguração da geopolítica mundial, bem como para situar o Brasil entre os países emergentes nesse contexto, particularmente em África. Ver neste sentido, Brics Policy/ Centro de Estudos e Pesquisas Brics (2009), Veloso e Luft (s. d.). Em relação a Moçambique têm predominado estudos sobre a presença da China (Chichava, 2008; Chichava e Alden, 2012).

6 A Vale está presente em 14 estados brasileiros e em países da América do Sul, da América do Norte, da América Central, da Europa, da Ásia, da Oceania.
} 
Quadro 1 - Presença da Vale em África, países, data de entrada e atividades

\begin{tabular}{|l|l|l|}
\hline \multicolumn{1}{|c|}{ País } & Data & \multicolumn{1}{c|}{ Atividades } \\
\hline África do Sul & 2004 & Estudo e desenvolvimento mineral \\
\hline Angola & 2005 & Estudo e desenvolvimento mineral \\
\hline Gabão & 2012 & Pesquisa de exploração mineral \\
\hline Guiné & 2006 & $\begin{array}{l}\text { Detém concessão para exploração de minério de } \\
\text { Ferro de Simandou (em revisão) }\end{array}$ \\
\hline Libéria & 2009 & $\begin{array}{l}\text { Projeto para desenvolver, financiar, operar manter } \\
\text { ferrovia e porto para escoamento de minério de ferro } \\
\text { da região do Simandou-Guiné }\end{array}$ \\
\hline Malawi & $\begin{array}{l}\text { Recuperação da ferrovia da Sociedade do Corredor } \\
\text { Norte S.A. tendo em vista o escoamento do carvão } \\
\text { produzido pela Vale em Moatize, Moçambique }\end{array}$ \\
\hline Moçambique & 2004 & $\begin{array}{l}\text { Extração de carvão em Moatize - projeto Evate, } \\
\text { Nampula - rocha fosfática - ferrovias Moatize-Beira } \\
\text { e Moatize-Nacala, terminal portuário de Nacala }\end{array}$ \\
\hline República do \\
Congo & 2007 & $\begin{array}{l}\text { Atividades de estudo de validade da Mina Klumines, } \\
\text { no chamado "cinturão de cobre", onde pretende } \\
\text { desenvolver operação de cobre e cobalto com a } \\
\text { African Rainbow Minerals }\end{array}$ \\
\hline Zambia & 2010 & $\begin{array}{l}\text { Estudo e desenvolvimento mineral, projeto da Mina } \\
\text { de Cobre a iniciar em 2013 }\end{array}$ \\
\hline
\end{tabular}

Fonte: Vale, $2012<$ www.vale.com/brasil/pt/aboutvale/across-world/paginas/default.aspx>.

O Projeto da Vale compõe, com outras empresas, os denominados mega projetos de mineração em Moçambique, identificados no Quadro 2.

Quadro 2 - Mega projetos de mineração: empresas e origem

\begin{tabular}{|l|l|l|}
\hline \multicolumn{1}{|c|}{ Produtos } & \multicolumn{1}{c|}{ Empresa } & \multicolumn{1}{c|}{ País } \\
\hline \multirow{5}{*}{ Gás Natural } & Suid Afrikaane Steenkool em Olie & África do Sul \\
\hline \multirow{5}{*}{ Petróleo } & Anadarko E.U.A. & E.U.A. \\
\cline { 2 - 3 } & Artumas & Canadá \\
\cline { 2 - 3 } & ENI & Itália \\
\cline { 2 - 3 } & Statoil Hydro & Noruega \\
\cline { 2 - 3 } & Petronas & Malásia \\
\cline { 2 - 3 } & BANG & E.U.A \\
\cline { 2 - 3 } & DNO & Nouega \\
\hline \multirow{3}{*}{ Carvão Mineral } & Companhia Vale do Rio Doce-Moatize & Brasil \\
\cline { 2 - 3 } & Riversdale Mining Ltd & Austrália \\
\hline
\end{tabular}

Fonte: Selemane (2011, p. 12). 


\section{A Vale em Moçambique}

Por ocasião da visita do Presidente Lula e de sua comitiva a Moçambique, em 2003, Celso Amorim, então Ministro das Relações Exteriores do Brasil, em artigo publicado na Folha de São Paulo, afirma:

as perspectivas para o redimensionamento de nossas relações políticas e econômico-comerciais são extremamente promissoras. A título exemplificativo, salientaria algumas das percepções e propostas que trouxe na bagagem. Identifiquei em Maputo um grande interesse moçambicano em contar com a participação do Brasil no projeto de exploração de carvão de Moatize, cujo potencial multiplicador de oportunidades não deve ser subestimado (Amorim, 2003).

No ano seguinte, a Vale iniciou suas atividades de pesquisa em Moçambique, após ter ganho o concurso internacional da concessão das minas de Moatize, lançado pelo governo de Moçambique. Em junho de 2007 é assinado contrato para a exploração do carvão mineral em Moatize entre a Vale e o governo de Moçambique. O contrato inclui, além da concessão da extração do carvão, a instalação de uma central térmica elétrica e investimentos na manutenção e construção de infraestrutura para o escoamento da produção, isto é, as ferrovias de Moatize a Beira e do corredor Nakala, esta com percurso no Malawi, bem como investimentos na infraestrutura portuária. A área ocupada para o desenvolvimento do Projeto da Vale é de 23.780 hectares (Mosca; Selemane, 2011, p. 20). A ocupação desta área implicou no reassentamento de 1313 famílias, assumido pela Vale.

A estrutura acionista do Projeto da Vale em Moatize tem a seguinte distribuição: $85 \%$ das ações pertencem à Vale, $5 \%$ ao estado Moçambicano e $10 \%$ a investidores moçambicanos (Mosca; Selemane, 2011, p. 19). As informações sobre os investimentos já feitos são desencontradas, variam entre 1.3 bilhões a 2 bilhões de dólares. Até sua conclusão os investimentos previstos são da ordem de US\$ 8,5 bilhões, o que corresponde a mais da metade do atual PIB do país (Mello, 2013). A multinacional IDC, o ramo do setor privado do Banco Mundial (IFC) e o Banco Nacional de Desenvolvimento Econômico e Social (Bndes-BR) são os principais financiadores (Mosca; Selemane, 2011, p. 20).

Para a atração destes investimentos deve ser considerada a política de incentivos adotada pelo governo Moçambicano, mediante isenção de impostos (direitos de importação sobre os bens de equipamento; impostos 
sobre capitais próprios ou empréstimos e respectivos juros) ou reduções (50\% da taxa de Contribuição Industrial, durante o período de até 10 exercícios fiscais; $80 \%$ quando realizados nas províncias de Niassa, Cabo Delgado e Tete; $65 \%$ quando se tratar de empreendimentos realizados fora das capitais provinciais), beneficiando empresas atuantes nos setores da agropecuária, indústria de transformação, pesca e derivados, construção civil, saúde e educação, infraestrutura (rodoviária, ferroviária, portuária e aeroportuária, telecomunicações, energia e águas) (Brasil, 2009, p. 19).

\section{Impactos e expectativas}

A instalação da Vale em Moatize teve um impacto na configuração das relações econômicas e sociais locais, tanto no município de Moatize, com menos de 30 mil habitantes, como na capital da Província, a cidade de Tete, com 155.870 habitantes.

Conforme levantamento feito em julho de 2011, o Projeto da Vale em Moatize absorvia 3.008 trabalhadores, sendo 2.684 moçambicanos e 324 estrangeiros, conforme Tabela 2. Há uma diferença expressiva entre os salários dos moçambicanos e estrangeiros. Enquanto o salário dos moçambicanos varia entre US\$113,00 e US\$ 4.814,00, o salário dos estrangeiros varia entre US\$ 665,00 e US\$ 17.677,00 (Mosca; Selemane, 2011, p. 30).

\section{Tabela 2 - Número de trabalhadores no Projeto da Vale em Moatize - julho de 2011}

\begin{tabular}{lcccccc}
\hline \multicolumn{1}{c}{ Empresa* } & \multicolumn{2}{c}{ Mulheres } & \multicolumn{2}{c}{ Homens } & \multicolumn{2}{c}{ Total } \\
\hline $\begin{array}{l}\text { Consórcio } \\
\text { (Moçambicanos) }\end{array}$ & 115 & $83,3 \%$ & 2569 & $89,5 \%$ & 2684 & $89,2 \%$ \\
$\begin{array}{l}\text { Osel } \\
\text { (Estrangeiros) }\end{array}$ & 23 & $16,7 \%$ & 301 & $10,5 \%$ & 324 & $10,8 \%$ \\
Totais & 138 & $100 \%$ & 2870 & $100 \%$ & 3008 & $100 \%$ \\
\hline
\end{tabular}

* O "Consórcio" congrega trabalhadores moçambicanos de várias empresas prestadoras de serviços ao projeto da Vale, e "Osel" congrega trabalhadores estrangeiros. O somatório de ambos perfaz o grupo total de trabalhadores do projeto da Vale em Moatize. Fonte: Mosca; Selemane (2011, p. 30).

Entre os mais variados efeitos da presença da Vale na Província, destacam-se alguns indicadores presentes, tanto para a cidade de Tete quanto de Moatize: ampliação do número de bancos em Tete e Moatize, que em 2007 eram cinco, passando a 11 em 2011. Aumento da demanda interna de serviços e consequente aumento da oferta de bens e serviços e emergência de novos pequenos negócios (habitação, transportes públicos, comércio, venda 
da pequena produção agrícola e pecuária etc.). Isto está levando, ainda, ao crescimento de atividades econômicas locais e nacionais, induzindo fluxos migratórios para atender serviços das empresas mineradoras. Por outro lado, o aumento da demanda, particularmente na área de alimentação, tem gerado um déficit no abastecimento e levado a um aumento das importações da África do Sul, com aumento do custo de vida afetando negativamente as condições de vida da população; crescimento do fluxo de passageiros, evidenciando a falta de infraestrutura de transporte. Além da imigração decorrente da carência de mão de obra qualificada local, os megaprojetos, como o da Vale, tornamse pontos de atração, gerando um crescimento demográfico e consequente crescimento desordenado das cidades (Mosca; Selemane, 2011). A população da Província de Tete, segundo os censos de 1997 e 2011, era de 1.038 .047 e 1.783.967, respectivamente, o que corresponde a um crescimento de mais de $70 \%$ em dez anos. ${ }^{7}$

As análises apontam algumas tensões em relação aos megaprojetos presentes em Moçambique. Nessa direção, Carlos Nuno Castel-Branco destaca que o

poder político pode estar orientado para construção e sustentação da apropriação privada dos recursos e rendas e acumulação privada do excedente produzido, sem uma perspectiva pública; estado focado na aliança entre o capital nacional e internacional; pobreza tem sentido retórica política e mobilização de ajuda externa; o problema dos grupos - territórios, género, geração. Cada um tem um argumento para justificar o seu direito social a rendas, como grupo, não como sociedade como um todo (Castel-Branco, 2013).

Outro aspecto salientado por Mosca e Selemane (2011) é o debate e a pressão que setores da sociedade moçambicana colocam em relação aos incentivos, o que tem levado a discussões e pressões para a revisão da legislação fiscal do setor de mineração e petrolífero.

Nesse contexto, emergiram protestos que têm a Vale como seu adversário. Em nível local, identificamos os protestos dos reassentados frente ao não cumprimento de compromissos da Vale acordados com as 1.365 famílias reassentadas decorrentes da ocupação da área destinada à mineração. Esses

\footnotetext{
7 Há um conjunto de questões recorrentes da implementação de grandes projetos em diferentes localidades, tanto na geração de novas oportunidades como fonte de conflitos em relação à polução local, migração de contingentes populacionais, particularmente masculino, disparidades salariais entre trabalhadores dentro de uma empresa e entre empresas, particularmente no processo de terceirização, questões ambientais, desalojamento de populações etc.
} 
protestos têm se articulado em nível transnacional e têm se colocado no rol de questões relacionadas aos megaprojetos, reconfigurando posicionamentos políticos de ONGs, organizações sindicais e instituições de pesquisa, acirrando o debate sobre os benefícios dos grandes projetos para a sociedade como um todo.

\section{Confrontos visíveis e tensões latentes}

A indenização não é suficiente. A população está muito zangada com a Vale. Se alguém puser fogo aqui, vai espalhar (Refo Agostinho Estanislau, um dos líderes do movimento dos reassentados da Vale - Moçambique).

Tornaram-se recorrentes, nos diversos meios de comunicação, notícias sobre confrontos de reassentados pela Vale em Moatize. ${ }^{8}$ As primeiras manifestações tiveram início em 2011 e, desde então, os manifestantes tem lançado mão a um repertório de confrontos que vão de petições, enviadas ao governo de Moçambique em 2011, para tomar providências para que a Vale cumprisse seus compromissos, passeatas frente à empresa até confrontos mais recentes com o bloqueio das estradas de acesso à mina da Vale em Moatize (abr./2013) e da ferrovia de escoamento do carvão (maio/2013) (Mello, 2013)9 com a intervenção do Estado. A pauta das demandas é o cumprimento dos compromissos assumidos pela Vale com as 1365 famílias reassentadas na região de Cateme e no Bairro 25 de Setembro (acesso à água, terra fértil, energia, indenização, bens coletivos de transporte, saúde, educação etc.). ${ }^{10}$ Assim que inicialmente os confrontos se articulam em oposição à Vale como "o adversário". Nessa direção, esses confrontos se adensaram com

8 Protestos estão ocorrendo também em outros grandes projetos, como o ocorrido em junho de 2012, quando 25 famílias ocuparam o escritório da empresa anglo-australiana Rio Tinto (Africa Today, 2012). Além disso, tem colocado preocupações para outras empresas. Como se anuncia numa manchete da Folha de São Paulo (2013): "Camargo Corrêa tenta evitar conflito similar ao da Vale em Moçambique", a qual ganhou a concessão para construir a hidroelétrica de Mphanda Nkuwa, no rio Zambeze.

9 Ver também: "Moatize: Comunidades reassentadas pela Vale Moçambique impedem a saída de Comboio para a Beira" <www.ihu.unisinos.br/noticias/505627-moatize-comunidadesreassentadas-pela-vale-mocambique-impe $\% 20 \mathrm{dem}$-a-saida-de-comboio-para-a-beira>; Megaprojeto é alvo de protestos em Moçambique <www.portosenavios.com.br/site/noticiasdo-dia/portos-e-logistica/21578-megaprojeto-da-vale-e-alvo-de-protestos-em-mocambique $>$.

${ }^{10}$ Os impactos com a implantação dos grandes projetos com a quebra das redes sociais, das atividades econômicas são temas recorrentes em estudos. No Brasil esses estudos datam a partir da década de 1970 com a construção das hidroelétricas, a exemplo da Hidroelétrica de Itaipu, e se estende aos dias atuais. A presença desses projetos nem sempre levam à emergência de confrontos. 
o apoio de outras organizações moçambicanas (a ONG Justiça Ambiental, Casa Embondeiro, Associação de Assistência Jurídica a Comunidades AAJC, Acção Acadêmica para o Desenvolvimento das Comunidades Rurais - Adecru) e internacionais como a ONG "Articulação Internacional dos Atingidos pela Vale", ${ }^{11}$ o Greenpeace e a ONG Declaração de Berna. ${ }^{12}$ Frente às restrições políticas, as redes de solidariedade são tidas como um fator para encorajamento, ou ao que Sidney Tarrow denomina a alargamento de "estruturas de oportunidades políticas" (Tarrow, 2009, p. 39), que "validam" as demandas e os confrontos. Nesses confrontos define-se um campo de luta entre um "nós" e a Vale. Há que se observar que a definição de uma fronteira levou também ao posicionamento do governo neste embate. Os reassentados acusam órgãos do governo de não tomarem medidas em relação às suas demandas. Conforme ainda afirmam os membros da Acção Académica para o Desenvolvimento das Comunidades Rurais - Adecru, em relação à intervenção policial contra os manifestantes que bloquearam as estradas de acesso à mina da Vale em Moatize, em abril, e ao bloqueio da ferrovia em maio de 2013:13 "Em cada episódio se evidencia a conivência e cumplicidade, a fuga permanente à responsabilidade por parte da Vale e do governo de Moçambique" (Adecru, 2013). Por outro lado, o diretor de implantação de projetos da Vale em África, Ásia e Austrália reconhece alguns problemas técnicos em relação ao reassentamento, mas também responsabiliza o governo ao afirmar que "infelizmente, o governo por alguma limitação ainda não designou o segundo hectare...", mas, ao mesmo tempo, afirmou que "graças ao bom diálogo que existe entre o governo e as empresas, está sendo possível resolver os problemas em Cateme em relação à qualidade de infraestruturas e oportunidades para as pessoas sentirem que o projeto também veio para beneficiá-las". Salienta-se

11 Uma das formas da Articulação Internacional dos Atingidos pela Vale se definir é: "Somos brasileiros, chilenos, peruanos, argentinos, moçambicanos, canadenses, indonésios... Indignados com o saque cotidiano de riquezas que pertencem a nossos povos e se definirem" $<$ http://atingidospelavale.wordpress.com/quem-somos/>. Uma análise das condições de trabalho na Vale no Canadá, Brasil e em Moçambique e articulações ver Marshall (2012).

12 A política de pressão externa tem se efetivado a partir de diferentes iniciativas, como o Protesto contra a Vale realizado em janeiro de 2012, por ocasião da Rio+20, quando Jeremias Vunganhe, que integra a ONG moçambicana Justiça Ambiental, foi barrado no Aeroporto de São Paulo. Ou ainda, a eleição da Vale como a pior empresa do mundo pelo "Public Eye People", premiação realizada pelas ONGs Greenpeace e Declaração de Berna (Economia, 2013).

13 A partir das notícias acessadas, não fica claro o nível de organização dos assentados, entre os oleiros que exigem condições para a produção de tijolos, que fizeram os bloqueios em abril e maio de 2013, que resultaram em prisões, e a população do Bairro 25 de Setembro que realizaram outro bloqueio em protesto contra a qualidade das construções das casas, ocorrido em junho de 2013 . 
que esse tipo de problema afeta o poder de persuasão do Brasil na África e sua estratégia de aproximação com países pobres e a ter uma imagem diferente em comparação às "antigas potências "imperialistas"” (Mello, 2013).

Os confrontos que vêm ocorrendo em Moatize, que tiveram inicialmente a Vale como alvo, passaram a colocar em cena outros atores como o governo moçambicano e ativaram redes sociais locais e transnacionais. Em nível do que é noticiado, estas ações transcendem as reivindicações dos reassentados pela Vale e colocam questões, pelo menos potencialmente, em relação aos megaprojetos presentes em Moçambique. Nessa direção, parece-nos sintomático a afirmação do primeiro-ministro Alberto Vaquina, por ocasião da greve dos médicos moçambicanos: "A ilusão de que a existência de recursos minerais já começou a produzir rendimentos e por isso deveríamos aumentar os salários de todas as pessoas é algo irreal" (DW, 2013). A afirmação, além de denotar motivações e argumentos subjacentes às reivindicações dos médicos, acirrou um debate público sobre efeitos econômicos da presença dos megaprojetos e a fraca contribuição nas receitas do estado. Sintoma desta tensão pode ser identificado também no campo do sindicalismo. Por ocasião da cerimônia de lançamento da Semana do Trabalhador de 2013, o Secretário Geral da Organização dos Trabalhadores de Moçambique (OTM) - Central-sindical que tem sido apontada como estando a reboque do governo e do partido Frelimo - afirmou: "Devemos exigir o combate cerrado contra a corrupção que grassa o País, a transparência nos contratos de exploração dos recursos naturais e que o lado social do desenvolvimento seja efectivamente promovido e considerado" (Canalmoz, 2013).

Nesse sentido colocamos algumas questões que, para a sua análise, dependem de pesquisa e um envolvimento nas dinâmicas locais. Entre as questões coloca-se a pergunta em relação às repercussões e ao nível de articulação desses confrontos com outros setores da sociedade moçambicana. Como estes confrontos se articulam com o que podemos denominar de um movimento latente, isto é, com os questionamentos em relação à política interna relativa aos megaprojetos que produz riqueza sem fixá-la no país, não contribuindo para reduzir a dependência externa e consolidar a soberania política? Como afirma Castel-Branco: "o país tem muita riqueza que está a ser gerada e por outro lado está a sair e não está a ser utilizada para criar uma economia mais articulada" (Castel-Branco apud Silva, 2012). Em que medida a presença dos megaprojetos está implicando num deslocamento discursivo no campo político interno centrado sobre a construção da paz para o debate sobre o sentido do desenvolvimento? Em que medida estes movimentos estão a criar espaços, oportunidades e quebra de restrições políticas? 
Não há como responder a priori essas questões, dado que dependem de desdobramentos político num campo de processos de fixação consolidados, da imprevisibilidade do jogo político e da construção de quadros de referência na mobilização de consensos e identidades. Nesse sentido parece que a consolidação das relações entre Brasil e Moçambique (e África), no sentido de se estabelecerem como relações verticais ou horizontais, não depende somente de acordos de cooperação, mas das dinâmicas políticas internas e externas, em que a Vale é apenas um dos atores. É nessa direção que situo o debate atual sobre desenvolvimento, dependência e cooperação presente nas relações Sul-Sul.

\section{Referências}

Adecru. Vale criminaliza lideranças de famílias atingidas pelo "Projecto Carvão Moatize" < http://adecru.wordpress.com/> (13 mar. 2013).

África Today. Rio Tinto paga indemnizações na próxima semana, África Today, 29 jun. $2012<$ www.africatoday.co.ao/pt/economia/9349-Rio-Tinto-paga-indemnizaesprxima-semana.html> (13 mar. 2013).

AMORIM, C. L. N. O Brasil e o "renascimento africano". Folha de S. Paulo, p. A3, 25 maio $2003<$ www1.folha.uol.com.br/fsp/opiniao/fz2505200308.htm> (10 mar. 2013).

BANCO Mundial; Ipea. Ponte sobre o Atlântico Brasil e África Subsaariana: parceria Sul-Sul para o crescimento. Brasília: Banco Mundial, Ipea, 2011 (13 mar. 2013).

BRASIL, Oportunidade de negócios em serviços - Moçambique. Brasília, Ministério do Desenvolvimento, Indústria e Comércio Exterior-MDIC, 2009 <www. desenvolvimento.gov.br/arquivos/dwnl_1256919989.pdf> (mar. 2013).

BRICS Policy Center/Centro de Estudos e Pesquisas Brics. Guia e fontes de pesquisa sobre os Brics. Rio de Janeiro <http://bricspolicycenter.org/homolog/arquivos/ GUIAEFONTE.pdf>.

BRITO, L. de et. al. Desafios para Moçambique, 2010. Maputo: Iese, 2009.

BRITTO, Gustavo et. al. Relatório final do estudo transversal "Perspectivas da política industrial nos Brics", Instituto de Economia da Universidade Federal do Rio de Janeiro e Instituto de Economia da Universidade Estadual de Campinas, em 2008-2009.

CANALMOZ. OTM Central Sindical ataca secretismo nos contratos mineiros. Canalmoz, 25 abr. 2013. <www.canalmoz.co.mz/hoje/24927-otm-central-sindicalataca-secretismo-nos-contratos-mineiros-.html> (12 mar. 2013).

CASTEL-BRANCO, C. N. Desafios da indústria extractiva em Moçambique. Maputo: Iese, $2013<$ www.iese.ac.mz/lib/noticias/2013/Oxafam_CNCB.pdf> (12 mar. 2013).

CHICHAVA, S.; ALDEN, C. A mamba e o dragão: relações Moçambique-China em perspectiva. Maputo: Iese/Saiia, 2012.

CHICHAVA, S. Mozambique and China: from politics to business? Discussion Paper Iese, $n^{\circ}$ 05/2008, Maputo <www.iese.ac.mz/lib/publication/dp_2008/DP_05_ MozambiqueChinaDPaper.pdf> (15 mar. 2013). 
COSTA, J. J. As relações Brasil-África no século 21: da aproximação seletiva à aproximação diversificada. In: $3^{\circ}$ Encontro Nacional da Associação Brasileira de Relações Internacionais, 2011, São Paulo <www.proceedings.scielo.br/pdf/enabri/ n3v2/a39.pdf $>$ (15 abr. 2013).

DEUTSCHE WELLE. "Megaprojetos deviam estar a beneficiar moçambicanos", dizem críticos. 5 jun. $2013<$ www.dw.de/megaprojetos-deviam-estar-a-beneficiarmo\%C3\%A7ambicanos-dizem-cr\%C3\%ADticos/a-16860766> (15 jun. 2013).

FOLHA DE SÃO PAULO. Camargo Corrêa tenta evitar conflito similar ao da Vale em Moçambique. Folha de São Paulo, 22 abr. 2013 <www1.folha.uol.com.br/ mundo/2013/04/1266524-camargo-correa-tenta-evitar-conflito-similar-ao-da-valeem-mocambique.shtml> (28 abr. 2013).

FUNDAÇÃO DOM CABRAL. Ranking das transnacionais brasileiras 2009: investimentos no exterior crescem, apesar da crise mundial. Nova Lima: FDC, 2009 $<$ www.fdc.org.br/pt/publicacoes/Paginas/RelatoriosDePesquisas.aspx> (22 fev. 2013).

FUNDAÇÃO DOM CABRAL. Ranking das transnacionais brasileiras 2010: repensando as estratégias globais. Nova Lima: FDC, $2010<$ www.fdc.org.br/pt/ publicacoes/Paginas/RelatoriosDePesquisas.aspx> (22 fev. 2013).

FUNDAÇÃODOMCABRAL.Rankingdastransnacionaisbrasileiras 2011:crescimento e gestão sustentável no exterior. Nova Lima;São Paulo e Belo Horizonte, FDC, 2011 $<$ www.fdc.org.br/pt/publicacoes/Paginas/RelatoriosDePesquisas.aspx> (22 fev. 2013).

GARCIA, Ana E. Saggioro. A internacionalização de empresas brasileiras durante o governo Lula: uma análise crítica da relação entre capital e estado no Brasil contemporâneo. 2012, 413f. Tese (Doutorado em Relações Internacionais) - Instituto de Relações Internacionais. Pontifícia Universidade Católica do Rio de Janeiro, Rio de Janeiro, 2012 <www.fisyp.org.ar/media/uploads/0812659_2012_completa.pdf> (15 mar. 2013).

IGLESIAS, R.; COSTA, K. O investimento direto brasileiro na África: características, condicionantes e perspectivas. Pontes, v. 8, n. 2, $2012<\mathrm{http}$ ://ictsd.org/i/news/pontes/ 130545/> (22 fev. 2013).

LOURENÇO, Luana. Na Etiópia, Dilma defende padrão Sul-Sul de cooperação com a África. Agência Brasil. Brasília, 25 maio $2013<$ http://agenciabrasil.ebc.com.br/ noticia/ 2013-05-24/na-etiopia-dilma-defende-padrao-sul-sul-de-cooperacao-comafrica> (27 maio 2013).

MARSHALL, J. Mega-projectos de mineração e trabalho: trabalhar para a vale "a pior empresa do mundo": casos do Canadá, Brasil e Moçambique. III Conferência Internacional do Iese "Moçambique: acumulação e transformação em contexto de crise internacional". Maputo, 2012. <www.iese.ac.mz/lib/publication/III_Conf2012/ IESE_IIIConf_Paper21.pdf> (2 mar. 2013).

MELLO, P. M. Megaprojeto da Vale é alvo de protestos em Moçambique. Folha de São Paulo, São Paulo, 22 abr. 2013 <www1.folha.uol.com.br/mundo/2013/04/1266520megaprojeto-da-vale-e-alvo-de-protestos-em-mocambique.shtml $>$ (22 fev. 2013).

MOSCA, J.; SELEMANE, T. El dorado Tete: os mega projectos de mineração. Maputo: Centro de Integridade Pública, 2011 <www.cip.org.mz/cipdoc/106_EL\%20 DORADO\%20TETE_Mosca\%20e\%20Selemane_CIP_2011.pdf $>$ (22 fev. 2013). 
O ESTADO DE SÃO PAULO. Vale é eleita por ONGs 'pior empresa do mundo', São Paulo, 27 jan. $2012<$ www.estadao.com.br/noticias/impresso,vale-e-eleita-por-ongspior-empresa-do-mundo-,827836,0.htm> (22 fev. 2013).

PIMENTEL, J. V. de S. Relações entre o Brasil e a Àfrica subsaárica. Revista Brasileira de Política Internacional, v. 43, n. 1, 2000.

POCHMANN, M. Prefácio. In: Banco Mundial; Ipea. Ponte sobre o Atlântico Brasil e África Subsaariana: parceria Sul-Sul para o crescimento. Brasília, Banco Mundial, Ipea, 2011 <www.ipea.gov.br/portal/index.php?option=com content\&view $=$ article\&id=12637> $(10$ mar. 2013) .

RIBEIRO, Cláudio Oliveira. Adjustment changes: a política africana do Brasil no Pós-Guerra Fria. Sociologia Política, v. 18, n. 35, p. 55-79, 2010.

ROSA, M. C. Landless: Meanings and transformations of a collective action category in Brazil. Agrarian South: journal of political economy, v. 1, p. 205-231, 2012.

ROSA, M. C. Reforma agrária e "land reform": movimentos sociais e o sentido de ser um sem-terra no Brasil e na África do Sul. Caderno CRH, v. 25, p. 99-114, 2012a.

SELEMANE, T. Alguns desafios na indústria extractiva em Moçambique. Maputo: Centro de Integridade Pública, 2009.

SILVA, A. da C. e. Um rio chamado Atlântico: a África no Brasil e o Brasil na África. Rio de Janeiro: Nova Fronteira, 2003.

SILVA, Romeu. População em Moçambique ainda não beneficia de mega-projetos $<$ www.dw.de/popula\%C3\%A7\%C3\%A3o-em-mo\%C3\%A 7 ambique-aindan\%C3\%A3o-beneficia-de-mega-projetos/a-16237283> (28 abr. 2013).

SOARES, E. V. Literatura e estruturas de sentimento: fluxos entre Brasil e África. Sociedade e Estado, v. 26, n. 2, p. 95-112, 2011.

TARROW, S. O poder em movimento. Petrópolis: Editora Vozes, 2009.

VALE. A Vale no Mundo <www.vale.com/brasil/pt/aboutvale/across-world/paginas/ default.aspx $>$ (2 mar. 2013).

VELOSO, J. P.; LUFT, L. A crise global e o novo papel mundial dos Brics. Rio de Janeiro: J. Olympio, 2009.

VILAS-BÔAS, Júlia Covre. Os investimentos brasileiros na África no governo Lula: um mapa. Meridiano 47, v. 12, n. 128, p. 3-9, $2011<\mathrm{http}$ ://periodicos.bce.unb.br/ index.php/MED/article/view/4242/4749> (28 abr. 2013).

VIZENTINI, P. G. F. Ensaios FEE, v. 20, n. 1, p. 134-154, 1999.

Data de recebimento: 15 jul. 2013

Data de aprovação: 25 nov. 2013

Autor correspondente:

Remo Mutzenberg

UFPE - Departamento de Sociologia

Avenida da Arquitetura, s/n. CFCH, $12^{\circ}$ andar

Cidade Universitária

50740-550 Recife, PE 